\title{
PEMETAAN LOKASI POTENSI DESA WISATA DI KABUPATEN SLEMAN TAHUN 2015
}

\author{
Akhmad Fauzy' dan Anggara Setyabawana Putra ${ }^{2}$ \\ 1,2Prodi Statistika, FMIPA UII Yogyakarta \\ Email: akhmad.fauzy@uii.ac.id
}

\begin{abstract}
These last few years, a lot of tourism village appeared in various regions, as well as in Sleman, Yogyakarta. Department of Tourism and Culture Sleman, noted, until 2015 there were a total of 35 tourism village with a variety of categories. With many of the tourism village, is necessary to manage the tourism village well. Mapping the location of the tourism village in Sleman district, conducted to provide ease of access roads to tourist sites for tourists domestic and foreign tourists. Software used is ArcGIS 10.I. with ArcGIS can make a map of Tourism Village Location Sleman 2015.
\end{abstract}

Keywords: Tourism Village, Maps, ArcGIS

\section{PENDAHULUAN}

Daerah Istimewa Yogyakarta (DIY) menyimpan beragam potensi wisata yang menarik. Salah satu daerah yang memiliki potensi wisata adalah di Kabupaten Sleman. Secara geografis Sleman terletak di $110^{\circ} 33^{\prime} 0^{\prime \prime}$ dan $110^{\circ} 13^{\prime} 0^{\prime \prime}$ bujur timur, $7^{0} 34^{\prime} 51^{\prime \prime}$ dan $7^{0} 47^{\prime} 30^{\prime \prime}$ lintang selatan, sebelah utara berbatasan langsung dengan kabupaten Boyolali, sebelah barat dengan kabupaten Magelang dan Kulonprogo, selatan berbatasan dengan Kota Yogyakarta, Kabupaten Bantul dan Gunung Kidul, sedangkan sebelah timur berbatasan dengan Kabupaten Klaten. Kabupaten Sleman Memiliki Luas wilayah $574,82 \mathrm{~km}^{2}$ (Sleman, 2009). Salah satu potensi wisata yang ada di Kabupaten Sleman adalah potensi desa wisata. Desa wisata adalah bentuk integrasi antara atraksi, akomodasi dan fasilitas pendukung yang disajikan dalam suatu struktur kehidupan masyarakat yang menyatu dengan tata cara dan tradisi yang berlaku (Nuryanti,1993). Dinas Kebudayaan dan Pariwisata Kabupaten Sleman hingga tanggal 17 Maret 2015 mencatat sebanyak 38 desa wisata, dengan kemungkinan ke depan akan bertambah lagi dari jumlah sekarang. Dengan jumlah yang demikian banyak dan tersebar di berbagai daerah, diperlukan suatu menejemen yang tepat dalam tata kelolanya.

Pemetaan lokasi potensi desa wisata di kabupaten Sleman tahun 2015 bertujuan untuk memetakan daerah-daerah wisata dalam hal ini adalah desa wisata yang terletak di kabupaten Sleman, sehingga akan mempermudah dalam pengaksesan lokasi bagi para wisatawan ataupun instansi lain yang membutuhkan.

\section{A. Kepariwisataan}

Dalam UU No. 10 Tentang Kepariwisataan tahun 2009, istilah Kepariwisataan didefinisikan sebagai keseluruhan kegiatan yang terkait dengan pariwisata dan bersifat multidimensi serta multidisiplin yang muncul sebagai wujud kebutuhan setiap orang dan negara serta interaksi antara wisatawan dan masyarakat setempat, sesama wisatawan, Pemerintah dan Pemerintah Daerah, serta pengusaha. Upaya penyelenggaraan pariwisata, selain pemenuhan aspek ekonomi, harus didukung juga dengan aspek intelektual 
dan rohani. Tujuan kepariwisataan menurut UU Kepariwisataan tahun 2009 adalah:

1. meningkatkan pertumbuhan ekonomi,

2. meningkatkan kesejahteraan rakyat,

3. menghapus kemiskinan,

4. mengatasi pengangguran,

5. melestarikan alam, lingkungan, dan sumber daya,

6. memajukan kebudayaan,

7. mengangkat citra bangsa,

8. memupuk rasa cinta tanah air,

9. memperkukuh jati diri dan kesatuan bangsa,

10. mempererat persahabatan antarbangsa.

\section{B. Desa Wisata}

Desa wisata menurut Nuryanti (1993) merupakan suatu bentuk integrasi antara atraksi, akomodasi dan fasilitas pendukung yang disajikan dalam suatu struktur kehidupan masyarakat yang menyatu dengan tata cara dan tradisi yang berlaku. Beberapa aspek yang perlu diperhatikan dalam penetapan suatu desa wisata (Soemarno, 2010):

1. Aksesbilitasnya baik, sehingga mudah untuk dikunjungi wisatawan dengan menggunakan berbagai jenis alat transportasi.

2. Memiliki obyek-obyek menarik berupa alam, seni budaya, legenda, makanan local, dan sebagainya untuk dikembangkan sebagai obyek wisata.

3. Masyarakat dan aparat desanya menerima dan memberikan dukungan yang tinggi terhadap desa wisata serta para wisatawan yang datang ke desanya.

4. Keamanan di desa tersebut terjamin.

5. Tersedia akomodasi, telekomunikasi, dan tenaga kerja yang memadai.

6. Beriklim sejuk atau dingin.
7. Berhubungan dengan obyek wisata lain yang sudah dikenal oleh masyarakat luas.

\section{Peta}

Peta merupakan wahana bagi penyimpanan dan penyajian data kondisi lingkungan, merupakan sumber informasi bagi para perencana dan pengambilan keputusan pada tahapan dan tingkatan pembangunan (Bakosurtanal, 2005).

Peta adalah gambaran/proyeksi dari sebagian permukaan bumi pada bidang datar atau kertas dengan skala tertentu (Brinker, 1984). Peta dibagi menjadi 2 jenis, yaitu (Abidin, 2007):

1. Peta Topografi

Berisi kenampakan alam baik asli maupun buatan manusia, berfungsi sebagai peta dasar dalam pembuatan peta tematik (contoh: Peta Rupa Bumi).

2. Peta Tematik

Isi sesuai dengan tema, biasanya dignakan untuk analisis dalam bidang penelitian tertentu (contoh: peta jenis tanah).

Fungsi peta menurut Basofi (2013):

1. menunjukkan posisi/lokasi relatif (letak suatu tempat dengan tempat lain) di permukaan bumi,

2. memperlihatkan ukuran di atas permukaan bumi,

3. menggambarkan bentuk 2 permukaan bumi seperti benua, gunung, dan lainnya,

4. menyajikan data tentang potensi suatu daerah.

\section{METODE}

Data yang digunakan dalam penelitian ini adalah data sekunder berupa:

1. Data lokasi Desa Wisata di Kabupaten Sleman 
Tabel 1. Lokasi Desa Wisata

\begin{tabular}{|c|c|c|}
\hline No & Nama Desa Wisata & Lokasi \\
\hline 1 & Desa Wisata Brayut & Brayut, Desa Pendowoharjo, Kecamatan Sleman \\
\hline 2 & Desa Wisata Tanjung & Tanjung, Desa Donoharjo, Kecamatan Ngaglik \\
\hline 3 & Desa Wisata Sambi & Sambi, Desa Pekmbinangun, Kecamatan Pakem \\
\hline 4 & Desa Wisata Grogol & Grogol, Desa Margodadi, Kecamatan Mlati \\
\hline 5 & Desa Wisata Mlangi & Mlangi, Desa Nogotirto, Kecamatan Mlati \\
\hline 6 & Desa Wisata Plempuh & Plempuh, Desa Bokoharjo, Kecamatan Prambanan \\
\hline 7 & Desa Wisata Sorowulan & Sorowulan, Desa Puwobinangun, Kecamatan Pakem \\
\hline 8 & Desa Wisata Pajangan & Pajangan, Desa Pendowoharjo, Kecamatan Sleman \\
\hline 9 & Desa Wisata Pentingsari & Pentingsari, Umbulharjo, Kecamatan Cangkringan \\
\hline 10 & Desa Wisata Gondang & Gondang, Desa Umbulharjo, Kecamatan Cangkringan \\
\hline 11 & Desa Wisata Sengir & Sengir, Desa Wukirharjo, Kecamatan Prambanan \\
\hline 12 & Desa Wisata Nawung & Nawung, Desa Gayamharjo, Kecamatan Prambanan \\
\hline 13 & Desa Wisata Garongan & Garongan, Desa Wonokerto, Kecamatan Turi \\
\hline 14 & Desa Wisata Bokesan & Bokesan, Desa Sindumartani, Kecamatan Ngemplak \\
\hline 15 & Desa Wisata Gabungan & Gabungan, Desa Donokerto, Kecamatan Turi \\
\hline 16 & Desa Wisata Trumpon & Trumpon, Desa Merdikorejo, Kecamatan Tempel \\
\hline 17 & Desa Wisata Kelor & Kelor, Desa Bangunkerto, Kecamatan Turi \\
\hline 18 & Desa Wisata Ledoknongko & Ledoknongko, Desa Bangunkerto, Kecamatan Turi \\
\hline 19 & Desa Wisata Kembangarum & Kembangarum, Desa Donokerto, Kecamatan Turi \\
\hline 20 & Desa Wisata Temon & Temon, Desa Pendowoharjo, Kecamatan Sleman \\
\hline 21 & Desa Wisata Ketingan & Ketingan, Desa Tirtoadi, Kecamatan Mlati \\
\hline 22 & Desa Wisata Sendari & Sendari, Desa Tirtoadi, Kecamatan Mlati \\
\hline 23 & Desa Wisata Brajan & Brajan, Desa Sendangagung, Kecamatan Minggir \\
\hline 24 & Desa Wisata Gamplong & Gampong, Desa Sumberrahayu, Kecamatan Moyudan \\
\hline 25 & Desa Wisata Sangubanyu & Sangubanyu, Desa Sumberrahayu, Kecamatan Moyudan \\
\hline 26 & Desa wisata Malangan & Malangan, Desa sumberagung, Kecamatan Moyudan \\
\hline 27 & Desa Wisata Sukunan & Sukunan, Desa banyuraden, Kecamatan, Gamping \\
\hline 28 & Desa Wisata Jethak II & Jethak II, Desa Sidokarto, Kecamatan Godean \\
\hline 29 & Desa Wisata Kaliurang Timur & Kaliurang Timur, Desa Hargobinangun, Kecamatan Pakem \\
\hline 30 & Desa Wisata Turgo & Turgo, Desa Purwobinangun, Kecamatan Pakem \\
\hline 31 & Desa Wisata Tunggularum & Tunggularum, Desa Wonoerto, Kecamatan Turi \\
\hline 32 & Desa Wisata Nganggring & Nganggring, Desa Girikerto, Kecamatan Turi \\
\hline 33 & Desa wisata Kadisobo II & Kadisobo II, Desa Trimulyo, Kecamatan Sleman \\
\hline 34 & Desa Wisata Polesari & Polesari, Desa Wonokerto, Kecamatan Turi \\
\hline 35 & Desa Wisata Pancoh & Pancoh, Desa Girikerto, Kecamatan Turi \\
\hline 36 & Desa Wisata Kinahrejo & Kinahrejo, Desa Umbulharjo, Kecamatan Cangkringan \\
\hline
\end{tabular}

Sumber : Dinas Kebudayaan dan Pariwisata Kabupaten Sleman 2015

2. Peta RBI DIY skala $1: 25.000$

3. Peta Administrasi DIY 2008

4. Software Pemetaan Arcgis 10.1
Kemudian

dilakukan

pemetaan menggunakan teknik pemetaan digitasi. Digitasi adalah proses pengubahan data analog (Peta RBI) menjadi digital yang 
berstruktur vektor. Data vektor dapat disimpan dalam bentuk titik (point), garis (line) dan bidang (Poligon). Setelah dilakukan digitasi, kemudian memasukkan data seperti di bawah ini.

Tabel 2. Data Atribut

\begin{tabular}{|c|l|r|l|}
\hline FID & Shape & Id & \\
\hline 0 & Point & 0 & Desa Wisata Brayut \\
\hline 1 & Point & 0 & Desa Wisata Pajangan \\
\hline 2 & Point & 0 & Desa Wisata Temon \\
\hline 3 & Point & 0 & Desa Wisata Tanjung \\
\hline 4 & Point & 0 & Desa Wisata Sambi \\
\hline 5 & Point & 0 & Desa Wisata Turgo \\
\hline 6 & Point & 0 & Desa Wisata Pancoh \\
\hline 7 & Point & 0 & Desa Wisata Kaliurang Timur \\
\hline 8 & Point & 0 & Desa Wisata Tunggularum \\
\hline 9 & Point & 0 & Desa Wisata Pulesari \\
\hline 10 & Point & 0 & Desa Wisata Garongan \\
\hline 11 & Point & 0 & Desa Wisata Kembangarum \\
\hline 12 & Point & 0 & Desa Wisata Gabungan \\
\hline 13 & Point & 0 & Desa Wisata Ledoknongko \\
\hline 14 & Point & 0 & Desa Wisata Kelor \\
\hline 15 & Point & 0 & Desa Wisata Trumpon \\
\hline 16 & Point & 0 & Desa Wisata Gongdang \\
\hline 17 & Point & 0 & Desa Wisata Kinahrejo \\
\hline 18 & Point & 0 & Desa Wisata Bokesan \\
\hline 19 & Point & 0 & Desa Wisata Plempuh \\
\hline 20 & Point & 0 & Desa Wisata Mlangi \\
\hline 21 & Point & 0 & Desa Wisata Ketingan \\
\hline 22 & Point & 0 & Desa Wisata Sendari \\
\hline 23 & Point & 0 & Desa Wisata Sangubanyu \\
\hline 24 & Point & 0 & Desa Wisata Gamplong \\
\hline 25 & Point & 0 & Desa Wisata Malangan \\
\hline 26 & Point & 0 & Desa Wisata Grogol \\
\hline 27 & Point & 0 & Desa Wisata Jethak II \\
\hline 28 & Point & 0 & Desa Wisata Banyuraden \\
\hline 29 & Point & 0 & Desa Wisata Kadisobo II \\
\hline 30 & Point & 0 & Desa Wisata Brajan \\
\hline 31 & Point & 0 & Desa Wisata Ngangring \\
\hline 32 & Point & 0 & Desa Wisata Sorowulan \\
\hline 34 & Point & 0 & Desa Wisata Sengir (Rumah Dome) \\
\hline & Point & 0 & Desa Wisata Nawung \\
\hline
\end{tabular}


Setelah memasukkan data atribut, maka dilakukan proses layout dengan menambahkan unsur-unsur peta lainya.

\section{HASIL DAN PEMBAHASAN}

Dari proses pemetaan yang telah dilakukan, berupa digitasi, didapatkan titik-titik lokasi seperti di bawah ini.

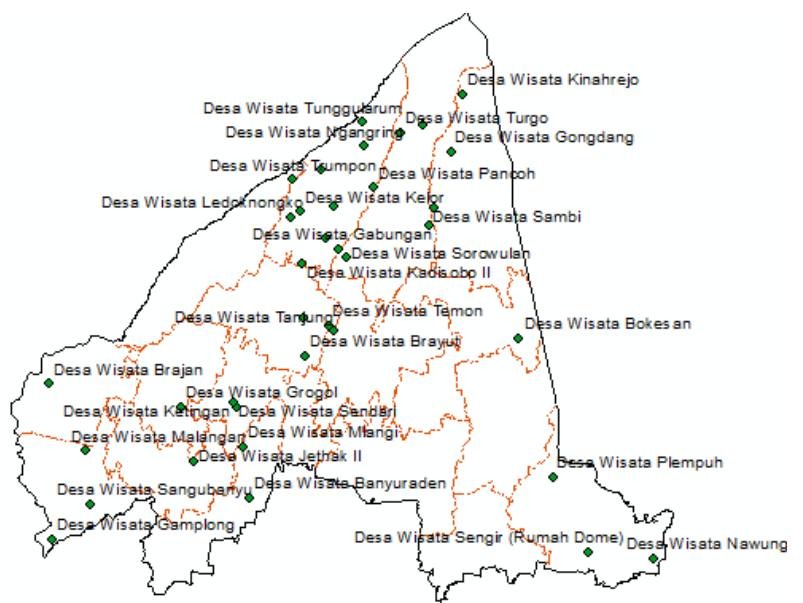

Gambar 1. Hasil digitasi
Data atribut yang telah dimasukkan dapat ditampilkan seperti di bawah ini.

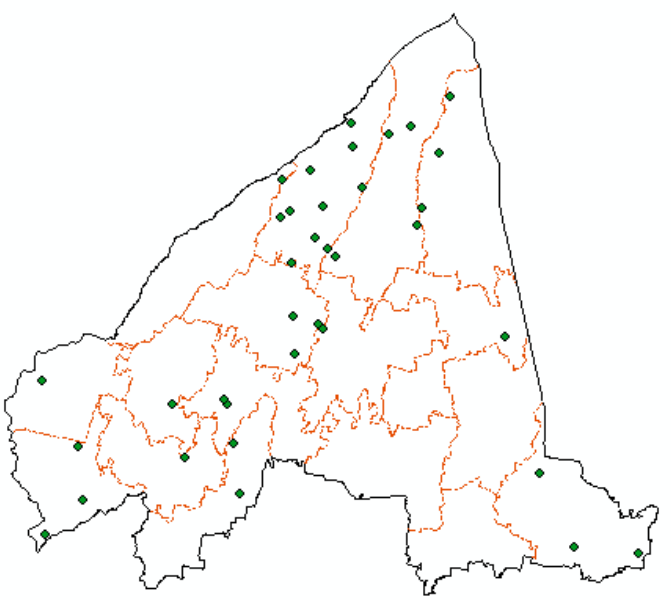

Gambar 2. Label Features

Kemudian dilakukan layout peta, yaitu penambahan keterangan dan unsur peta lainya. Hasil layoutnya seperti di bawah ini.

\section{PETA POTENSI DESA WISATA KABUPATEN SLEMAN TAHUN 2015}

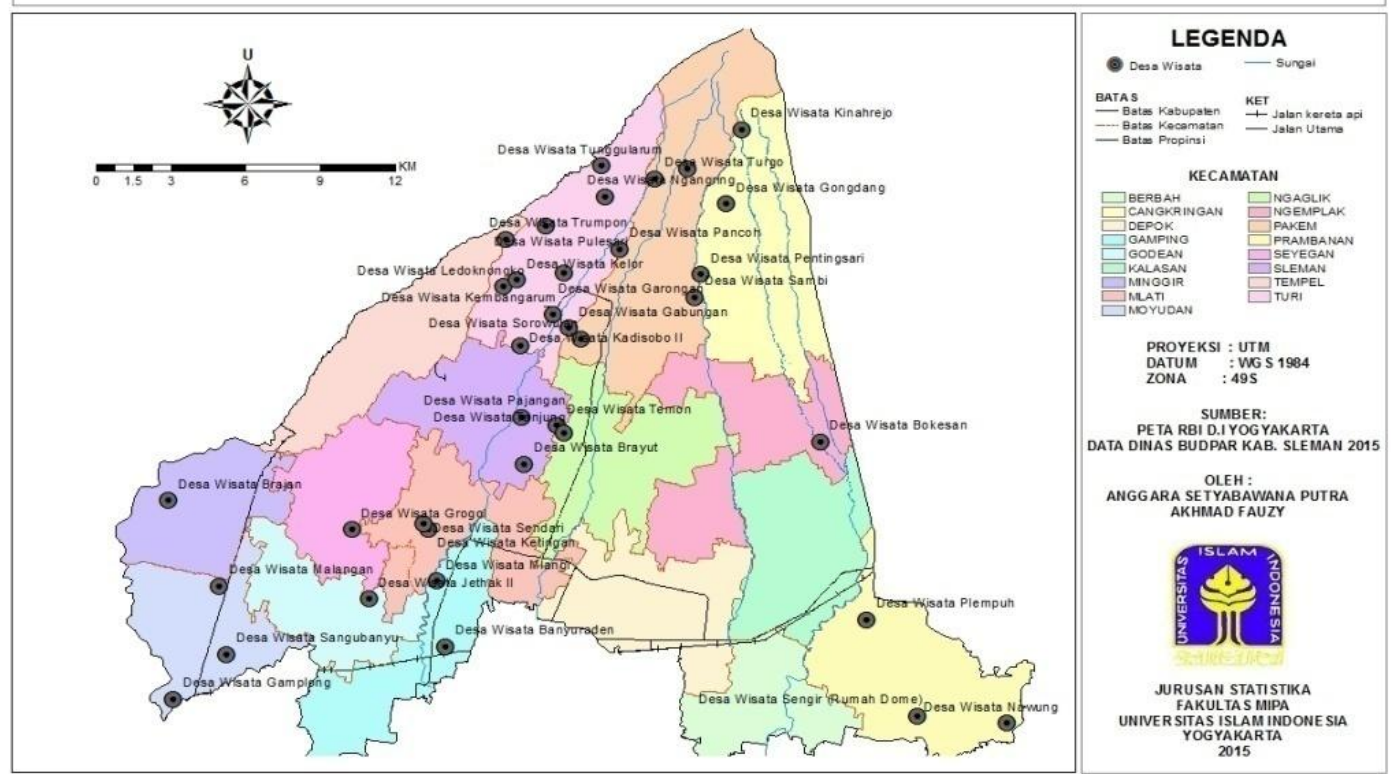

Gambar 3. Peta Potensi Desa Wisata Kabupaten Sleman 2015 


\section{KESIMPULAN DAN SARAN}

\section{A. Kesimpulan}

Pemetaan lokasi desa wisata dapat memberikan kemudahan bagi para wisatawan untuk pengaksesan lokasi dan pemilihan desa wisata yang akan dituju. Pembuatan database desa wisata, dapat digunakan untuk memperbaharui data secara realtime untuk kepentingan pemetaan.

\section{B. Saran}

1. Dengan semakin banyaknya jumlah desa wisata yang ada di Kabupaten Sleman, perlu kiranya dibuat peraturan yang mengatur akan desa wisata, yang dikeluarkan oleh pemerintah daerah ataupun instansi terkait, sehingga segala hal yang berkaitan dengan desa wisata dapat tertata dan diatur dengan baik.

2. Penelitian yang dilakukan, dapat dikembangkan dengan menambahkan data andministrasi dan utility di daerah setempat.

\section{UCAPAN TERIMAKASIH}

Ucapan terima kasih disampaikan yang sebesar-besarnya kepada DPPM UII dan Direktorat Penelitian dan Pengabdian Masyarakat (Dirlitabmas). Direktorat Jenderal Pendidikan Tinggi (Dirjen Dikti), Kementerian Pendidikan dan Kebudayaan atas dibiayainya penelitian ini melalui skema Hibah Bersaing tahun 2015 dengan nomor kontrak 028/Rek/70/DPPM/Hibah Bersaing LanjutanDIKTI/III/2015.

\section{DAFTAR PUSTAKA}

Abidin, H. Z. 2007. Konsep Dasar Pemetaan. Bandung: ITB. Kelompok Keilmuan Geodesi. http://geodesy.gd.itb.ac.id/hzabidin/wpcontent/uploads/2007/05/konsep-dasarpemetaan.pdf diakses: 17 Maret 2015.
Bakosurtanal. 2005. Pengertian Peta (Online).http://geografi.com/2009/09/ pengertian-peta.htm diakses: 18 Maret 2015.

Basofi. 2013. Jenis-Jenis dan Fungsi Peta. Surabaya: Pens http://ariv.lecturer.pens.ac.id/G.I.S/0I Teori/M04.\%20Jenis\%20\&\%20Fungsi\%20 Peta.pdf diakses: 18 Maret 2015.

Brinker, R. C. 1984. Dasar-Dasar Pengukuran Tanah (Surveying). Jakarta: Erlangga

Nuryanti, Wiendu. 1993. Concept, Perspective and Challenges, makalah bagian dari Laporan Konferensi Internasional mengenai Pariwisata Budaya. Yogyakarta: Gadjah Mada University Press.

Sleman. 2009. Laporan Akuntabilitas Kinerja Instansi Pemerintah Kabupaten Sleman Tahun 2009. http://www.slemankab.go.id/wpcontent/uploads/05.-Bab- I-09.pdf diakses: 20 Maret 2015.

Soemarno. 2010. Desa Wisata.

Marno.lecture.ub.ac.id/files/2012/0I/ Desawisata.doc diakses: 19 Maret 2015.

Undang-Undang Republik Indonesia Nomor 10. Tahun 2009 Tentang Kepariwisataan 